\title{
Utilisation des corticostéroïdes intranasaux
}

\author{
James Fowler MD, Leigh J Sowerby MD
}

Citation : CMAJ 2021 January 11;193:E47. doi : 10.1503/cmaj. 201266-f

Voir la version anglaise de l'article ici : www.cmaj.ca/lookup/doi/10.1503/cmaj.201266

1

Les corticostéroïdes intranasaux peuvent

être utilisés comme traitement principal ou d'appoint pour plusieurs affections inflammatoires de la cavité nasale

Environ $5 \%$ de la population canadienne souffre d'inflammation sinonasale ${ }^{1}$. Les experts s'entendent généralement sur l'efficacité des corticostéroïdes intranasaux à traiter la rhinite allergique et non allergique, la rhinosinusite aiguë et la rhinosinusite chronique, avec et sans polypose nasale ${ }^{2,3}$.

Il y a 9 corticostéroïdes intranasaux approuvés au Canada, tous d'une efficacité similaire Les corticostéroïdes intranasaux agissent sur les réponses inflammatoires hâtives et tardives en inhibant la production de cytokines proinflammatoires et d'enzymes inflammatoires, sur la prolifération des lymphocytes et sur l'hypersensibilité différée ${ }^{2,3}$. Même si l'efficacité des différents corticostéroïdes est similaire ${ }^{2}$, certains types ont des indications spécifiques (annexe 1, accessible en anglais au www.cmaj.ca/lookup/ doi/10.1503/cmaj.201266/tab-related-content). sécuritaires, mais les effets indésirables locaux sont fréquents

Une personne sur 10 présente des effets indésirables locaux, tels que sensation de brûlure,

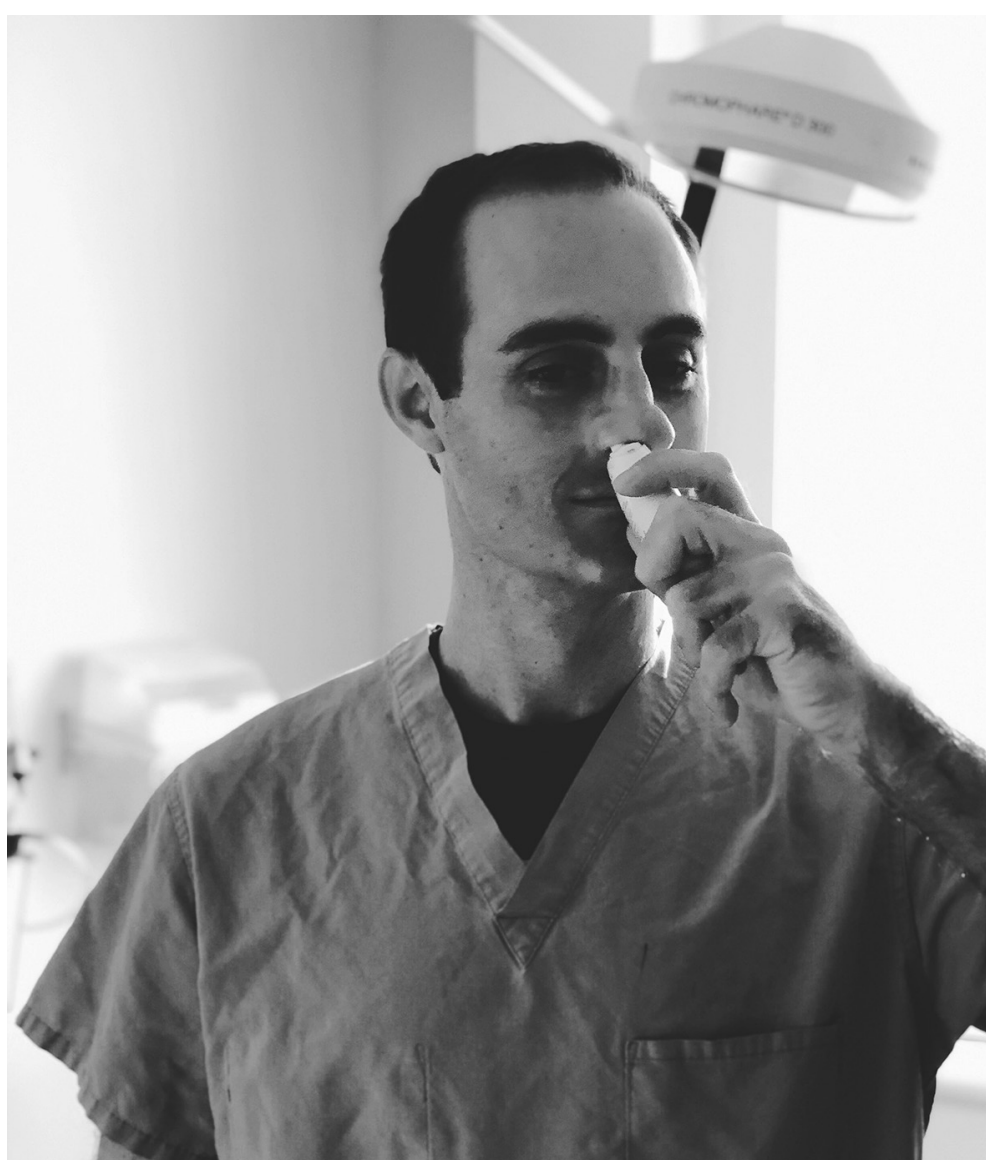

Figure 1 : Photographie de l'auteur (L.J.S.) montrant la technique d'administration des corticostéroïdes intranasaux avec la main controlatérale. picotements, sécheresse et épistaxis ${ }^{2}$. Les effets indésirables systémiques de ces agents sont très rares et il n'y a pas de corrélation entre leur utilisation et la suppression de l'axe hypothalamohypophyso-surrénalien ou une augmentation de la pression intraoculaire ${ }^{4}$. Une étude a établi un lien entre le dipropionate de béclométhasone et un ralentissement de la croissance chez les enfants ${ }^{4}$, mais aucun lien n'a été observé avec les autres corticostéroïdes intranasaux. Pour les personnes qui prennent concomitamment des corticostéroïdes par inhalation ou par voie orale, il y a un risque théorique d'accroissement des effets indésirables systémiques; on suggère dans ce cas un corticostéroïde en vaporisateur de seconde génération ayant une faible biodisponibilité (annexe 1$)^{5}$.

\section{4 \\ La bonne technique d'administration des corticostéroïdes intranasaux est cruciale pour obtenir l'effet thérapeutique désiré}

Les professionnels de la santé doivent enseigner à leur patientèle à ne pas orienter l'applicateur intranasal vers le septum nasal. On y arrive plus facilement en utilisant la main controlatérale pour s'administrer le corticostéroïde (figure 1). Une bonne technique réduira les effets indésirables locaux et favorisera l'observance 
thérapeutique. Il faut souvent administrer le médicament quotidiennement pendant 8-12 semaines pour obtenir l'effet thérapeutique complet, mais l'observance thérapeutique peut être affectée par le coût (annexe 1).

\section{Il y a moins de corticostéroïdes intranasaux pour 3 les enfants et les femmes enceintes}

Pour les enfants, le fuorate de mométasone ( $\geq 3$ ans), le propionate de fluticasone ( $\geq 4$ ans), l'acétonide de triamcinolone ( $\geq 4$ ans) et le ciclésonide ( $\geq 6$ ans) sont approuvés actuellement $^{2}$. Le budésonide est le seul corticostéroïde intranasal dont l'innocuité pendant la grossesse a été établie ${ }^{6}$.

\section{Références}

1. Kaplan A. Canadian guidelines for chronic rhinosinusitis: clinical summary. Can Fam Physician 2013;59:1275-81.

2. Wise SK, Lin SY, Toskala E, et al. International consensus statement on allergy and rhinology: allergic rhinitis. Int Forum Allergy Rhinol 2018;8:108-352.

3. Orlandi RR, Kingdom TT, Hwang PH, et al. International consensus statement on allergy and rhinology: rhinosinusitis. Int Forum Allergy Rhinol 2016;6:S22-209.

4. Gupta R, Fonacier LS. Adverse effects of nonsystemic steroids (inhaled, intranasal, and cutaneous): a review of the literature and suggested monitoring tool. Curr Allergy Asthma Rep 2016;16:44.
5. Juniper EF, Ståhl E, Doty RL, et al. Clinical outcomes and adverse effect monitoring in allergic rhinitis. J Allergy Clin Immunol 2005;115(Suppl 1):S390-413.

6. Alhussien AH, Alhedaithy RA, Alsaleh SA. Safety of intranasal corticosteroid sprays during pregnancy: an updated review. Eur Arch Otorhinolaryngol 2018;275:325-33.

Intérêts concurrents : Leigh Sowerby signale avoir reçu des honoraires personnels de Mylan, GSK et Sanofi, et des subventions de GSK, Roche et AstraZeneca, indépendamment des travaux soumis. Aucun autre intérêt concurrent n'a été déclaré.

Cet article a été révisé par des pairs.

Affiliation : Département d'otorhinolaryngologie et de chirurgie cervico-faciale, Université Western, London, Ont.

Propriété intellectuelle du contenu : Il s'agit d'un article en libre accès distribué conformément aux modalités de la licence Creative Commons Attribution (CC BY-NC-ND 4.0), qui permet l'utilisation, la diffusion et la reproduction dans tout médium à la condition que la publication originale soit adéquatement citée, que l'utilisation se fasse à des fins non commerciales (c.-à-d., recherche ou éducation) et qu'aucune modification ni adaptation n'y soit apportée. Voir : https://creativecommons.org/licenses/by-nc-nd/4.0/deed.fr.

Correspondance : Leigh Sowerby, Leigh.Sowerby@sjhc.london.on.ca 